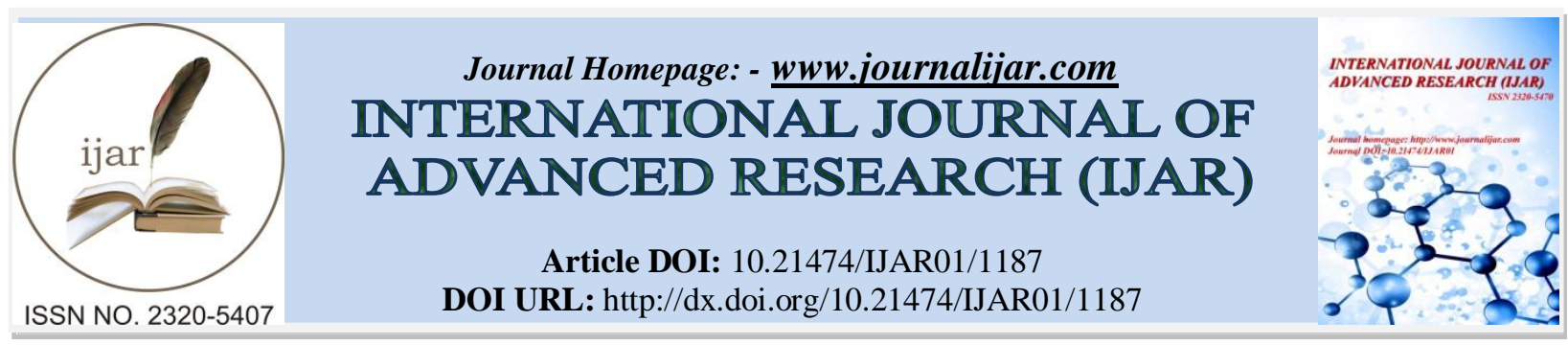

RESEARCH ARTICLE

\title{
REVELATION AND EASY MANAGEMENT OF RHOMBOIDS MUSCLE TRIGGER POINT AS A CAUSE OF DISTRESSING NON - CARDIAC CHEST PAIN- A CASE SERIES.
}

Mr. P Rajith ${ }^{1}$, Dr. Sharat Agarwal ${ }^{2}$, Mr. L. Anand ${ }^{3}$.

1. Physiotherapist, Dep't of Orthopedics \& Trauma, NEIGRIHMS, Shillong.

2. Associate Professor, Dep't of Orthopedics \& Trauma, NEIGRIHMS, Shillong.

3. Lecturer, College of Nursing NEIGRIHMS, Shillong.

\section{Manuscript Info}

Manuscript History

Received: 12 June 2016

Final Accepted: 19 July 2016

Published: August 2016

Key words:-

Myofascial pain, Trigger points,

Rhomboids muscle, Ischemic therapy

\section{Abstract}

Introduction:- Non-cardiogenic chest pain is a major health problem all over the world. Besides, non organic musculoskeletal pain affects up to $85 \%$ of the general population at any point of time. Patients with musculoskeletal chest pain remain under diagnosed, untreated and potentially continuously disabled in terms of anxiety, depression and ability to carry out activities of daily living [1]. Here we present a new dimension in this area by revealing Rhomboids muscle trigger point as the cause of referred chest pain, which in itself lacks enough description in the available literature.

Method: - A prospective study was conducted between January 2013 to September 2014 at Physiotherapy Unit in the Department of Orthopedics and Trauma of North Eastern Indira Gandhi Regional Institute of Health and Medical Science (NEIGRIHMS) Shillong, Meghalaya (India), a tertiary teaching health care institute which comprised of 30 patients with age group ranging from 12 yrs to $60 \mathrm{yrs}$. All patients were ruled out of cardiac and other known causes of chest pain by evaluating them based on a properly designed Performa. Ischemic pressure was applied on Rhomboids muscle after establishing Rhomboids muscle trigger point as the possible cause of chest pain. They were subjected to Ischemic pressure therapy and all of them had fulfilled the new ACR criteria for fibromyalgia. The duration of Ischemic pressure varied from 2 to 7 days, and subsequent follow up was done till 2 months. Visual Analogue scale (VAS) and Modified DALLAS Pain Questionnaire was used as measurement tool for assessing the treatment outcome.

Result: - The results were analysed by using two tailed paired ' $t$ ' test and was performed using SPSS version 20. The two-tailed P value of $<0.005$ considered extremely significant for our data.

Conclusion:- Our study has highlighted that while evaluating a clinician should remember that Rhomboid Muscle trigger point can be a distressing cause of chest pain and which can be effectively taken care of by Ischemic compression therapy. It may help such patients of "Non Specific cardiac chest pain" who otherwise run from pillar to post or one department to another, in vain. 
Non specific musculoskeletal chest pain is a major health problem all over the world. However, despite the apparently benign nature many times, patients with this problem remain under diagnosed, untreated and potentially continuously disabled in terms of anxiety, depression and to carry out normal activities of daily living (ADL).

The musculoskeletal structures of the thoracic wall and the neck are relatively common sources of chest pain. Pain arising from these structures is often mistaken for angina pectoris, pleurisy or other serious disorders [2]. Pain in the chest is a common symptom of diverse causes. It may have its origin in the thoracic wall, intrathoracic structures, neck or areas below the diaphragm $[3,4,5]$.

Musculoskeletal abnormalities are often suspected as the cause of chest pain. Their exact prevalence is unknown, but they have been noted in up to $10 \%$ of patients presenting with chest pain [6].

Musculoskeletal pain is a significant and common medical condition. Up to $85 \%$ of the general population will experience at least one episode of musculoskeletal pain during their lifetime [7].

Myofascial pain is one of the common presentations of musculoskeletal pain; an accumulating body of evidence suggests that unique hypersensitive loci, named myofascial trigger points in the literature, are intimately associated with the patho-physiology and clinical manifestation of myofascial pain [7].

Myofascial pain syndrome (MPS) is a form of myalgia that is characterized by local regions of muscle hardness that are tender and that cause pain to be felt at a distance i.e. referred pain. The central component of the syndrome is the trigger point that is composed of a tender, taut band. Stimulation of the band, either mechanically or with activity, can produce pain. Myofascial Pain Syndrome is a painful condition that is characterised by localised pain, muscle tenderness; decreased range of motion, mood and sleep problems. MFPS is diagnosed by the presence of multiple trigger points in the muscles. A Muscle Trigger point (MTrP) is described as "a hyperirritable spot in skeletal muscle that is associated with a hypersensitive palpable nodule in a taut band". Myofascial trigger points are classified into active and latent trigger points. An active MTrP is a symptom-producing MTrP and can trigger local or referred pain or other paresthesia [8].

According to the literature chest pain can be due to various reasons with spectrum ranging from life threatening conditions like acute coronary syndrome/ ischemic heart disease to non cardiac causes like pleurisy or pulmonary lessons like COPD, COAD and Bronchiectasis, Dysfunction of muscles and joints of the chest wall, Slipping ribs, Costochondritis, and Teitze syndrome [9].

Chest wall syndrome or conditions affecting chest wall, cervical and thoracic part of the spine like inflammatory rheumatologic conditions, infectious, gastro-intestinal problems and neoplastic disorders, can also be the other causes of non-cardiac chest pain [2].

Pain arising from the musculoskeletal structures of the shoulder, cervical spine or thoracic spine may be referred to areas in the chest wall with the same nerve supply. This referred pain is generally segmental or regional in distribution and "deep" in location (i.e., sclerotomal rather than dermatomal) [10].

Here, we present a new dimension in this area by revealing Rhomboids muscle trigger point as the cause of referred chest pain through the study conducted in NEIGRIHMS, Shillong, a condition which is not mentioned in the available literature. It is emphasized here that by this additional knowledge and awareness, morbidity of such patients of chest pain can be taken care of, to a significant extent.

\section{Aims:-}

To find out Rhomboids muscle trigger point as the cause of referred chest pain by using 'Ischemic Pressure Therapy'- which is a well established modality to manage trigger points and also to determine the effectiveness of 'Ischemic Pressure Therapy' in such a Non Cardiac chest pain. 


\section{Materials and Methods:-}

The study conducted was comprised of 30 patients (17 males and 13 females) with age group ranging from 12yrs to $60 y r s$. Patients were also assessed for fibromyalgia according to the new ACR fibromyalgia criteria (Widespread Pain Index (WPI) $>7$ and Symptom Severity Score (SS) $>5$ ) Or WPI 3-6 and SS >9 as per the American College of Rheumatology (ACR) Preliminary Diagnostic Criteria for Fibromyalgia and Measurement of Symptom Severity ACR Diagnostic criteria 2010 [11] and all 30 patients fulfilled the new ACR criteria for fibromyalgia. It was a prospective study conducted between January 2013 to September 2014 at Physiotherapy Unit at Department of Orthopedics and Trauma of North Eastern Indira Gandhi Regional Institute of Health and Medical Science (NEIGRIHMS) Shillong, Meghalaya, India.

All the patients who complained of chest pain were ruled out of cardiac and other known causes of chest pain by evaluating them based on a properly designed Performa. Ischemic pressure was applied on Rhomboids muscle after establishing Rhomboids muscle trigger point as the possible cause of chest pain. Trigger points in Rhomboids were identified. It was found that the ipsilateral, Rhomboids muscle caused pain in the same side of anterior chest. Pressure is applied slowly and progressively over the trigger point as the tension in the trigger point and its taut band subsides [12].

Pressure was maintained until the tenderness was gone or the tension was released. The pressure was gradually reapplied, maintained, and then gradually released. The pressure was held for as long as 60 seconds to 90 seconds. After a pause pressure was applied three or four more times, perhaps moving to another part of the muscle if the treated area felt 'looser' or softer to the touch. Initiation of pressure on to a trigger point was done gradually in an effort to minimize increases in tone, so as to get closer to the core of the trigger point [13].

The duration of Ischemic pressure therapy varied from 2 to 7 days, and subsequent follow up was done till 2 months. Visual Analogue scale (VAS) and Modified DALLAS Pain Questionnaire was used as measurement tool for assessing the treatment outcome.

We have modified DALLAS Pain Questionnaire, in which we have taken few components of the pain Questionnaire which we considered are relevant to the myofascial type of chest pain, under evaluation in our present study.

\section{Results:-}

Amongst the patients undertaken in the study 13 patients were female, ranging between 27 and 51 years, and 17 patients were male, ranging between 10 and 60 years

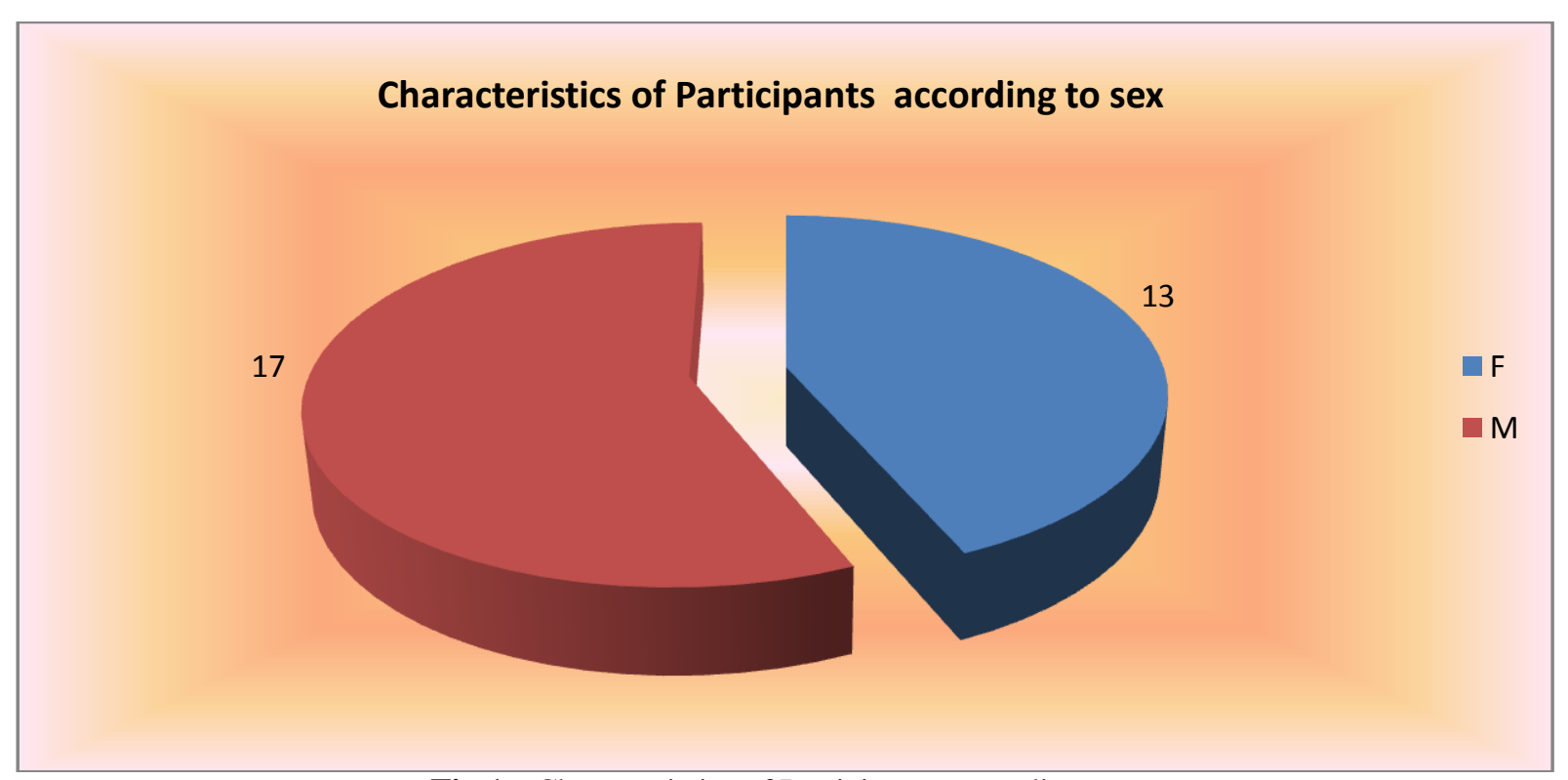

Fig.1:- Characteristics of Participants according to sex. 
The pie diagram shows the characteristics of participants according to sex. Out of 30 participants, 17(56.6\%) were males and $13(43.4 \%)$ were females.

Table 1:- A record of pre-treatment and post-treatment activities of 30 patients with complaint of chest pain.

\begin{tabular}{|c|c|c|c|c|c|c|c|c|c|c|c|c|}
\hline \multirow{3}{*}{$\begin{array}{l}\text { Patient } \\
\text { No. }\end{array}$} & \multirow{3}{*}{ Sex } & \multirow{3}{*}{$\begin{array}{c}\text { Age } \\
(y)\end{array}$} & \multicolumn{2}{|c|}{ VAS } & \multicolumn{8}{|c|}{ DAALLAS Pain Questionnaire } \\
\hline & & & \multirow{2}{*}{$\begin{array}{c}\text { Pre } \\
\begin{array}{c}\text { Out } \\
\text { of } 10\end{array} \\
\end{array}$} & \multirow{2}{*}{$\begin{array}{c}\text { Post } \\
\begin{array}{c}\text { Out } \\
\text { of } 10\end{array} \\
\end{array}$} & \multicolumn{2}{|c|}{$\begin{array}{c}\text { Daily } \\
\text { activities }\end{array}$} & \multicolumn{2}{|c|}{ Work/leisure } & \multicolumn{2}{|c|}{ Anxiety/depression } & \multicolumn{2}{|c|}{$\begin{array}{c}\text { Social } \\
\text { interest }\end{array}$} \\
\hline & & & & & Pre & Post & Pre & Post & Pre & Post & Pre & Post \\
\hline 1. & $\bar{F}$ & 27 & 7 & 0 & 52 & 9 & 30 & 5 & 25 & 5 & 35 & 5 \\
\hline 2. & $\bar{F}$ & 32 & 8 & 0 & 45 & 6 & 25 & 5 & 30 & 0 & 20 & 0 \\
\hline 3. & $F$ & 32 & 7 & 0 & 18 & 0 & 35 & 0 & 20 & 0 & 25 & 0 \\
\hline 4. & $\mathrm{~F}$ & 34 & 5 & 0 & 15 & 0 & 20 & 0 & 25 & 0 & 15 & 0 \\
\hline 5. & $\mathrm{~F}$ & 35 & 7 & 0 & 33 & 0 & 25 & 0 & 35 & 0 & 15 & 0 \\
\hline 6. & $F$ & 35 & 6 & 0 & 18 & 0 & 20 & 0 & 30 & 0 & 20 & 0 \\
\hline 7. & $\mathrm{~F}$ & 38 & 9 & 1 & 72 & 0 & 40 & 0 & 45 & 0 & 45 & 0 \\
\hline 8. & $\mathrm{~F}$ & 39 & 7 & 0 & 18 & 0 & 25 & 0 & 40 & 0 & 20 & 0 \\
\hline 9. & $F$ & 41 & 6 & 0 & 21 & 0 & 30 & 0 & 25 & 0 & 20 & 0 \\
\hline 10. & $\mathrm{~F}$ & 42 & 9 & 0 & 42 & 0 & 50 & 0 & 20 & 0 & 35 & 0 \\
\hline 11. & $\mathrm{~F}$ & 45 & 6 & 0 & 21 & 0 & 15 & 0 & 40 & 0 & 20 & 0 \\
\hline 12. & $\mathrm{~F}$ & 50 & 6 & 0 & 21 & 0 & 20 & 0 & 30 & 0 & 10 & 0 \\
\hline 13. & $\mathrm{~F}$ & 51 & 9 & 0 & 69 & 3 & 45 & 0 & 35 & 5 & 15 & 0 \\
\hline 14. & $\mathrm{M}$ & 10 & 5 & 0 & 33 & 3 & 15 & 0 & 25 & 5 & 10 & 0 \\
\hline 15. & $\mathrm{M}$ & 12 & 9 & 0 & 57 & 6 & 20 & 0 & 65 & 0 & 35 & 0 \\
\hline 16. & $\mathrm{M}$ & 16 & 7 & 0 & 21 & 0 & 20 & 0 & 70 & 10 & 35 & 5 \\
\hline 17. & $\mathrm{M}$ & 22 & 7 & 0 & 33 & 0 & 25 & 0 & 30 & 0 & 30 & 0 \\
\hline 18. & $\mathrm{M}$ & 28 & 8 & 0 & 36 & 3 & 20 & 0 & 55 & 0 & 25 & 0 \\
\hline 19. & $\mathrm{M}$ & 28 & 8 & 0 & 39 & 0 & 25 & 0 & 40 & 0 & 35 & 0 \\
\hline 20. & $\mathrm{M}$ & 34 & 7 & 0 & 40 & 3 & 30 & 5 & 35 & 0 & 20 & 0 \\
\hline 21. & $\mathrm{M}$ & 35 & 6 & 0 & 36 & 0 & 25 & 0 & 30 & 0 & 15 & 0 \\
\hline 22. & $\mathrm{M}$ & 38 & 8 & 0 & 36 & 0 & 45 & 0 & 25 & 0 & 35 & 0 \\
\hline 23. & $\mathrm{M}$ & 41 & 8 & 0 & 36 & 3 & 40 & 0 & 45 & 0 & 25 & 0 \\
\hline 24. & $\mathrm{M}$ & 42 & 8 & 0 & 36 & 0 & 15 & 0 & 20 & 0 & 25 & 0 \\
\hline 25. & $\mathrm{M}$ & 45 & 6 & 0 & 27 & 0 & 10 & 0 & 30 & 0 & 20 & 0 \\
\hline 26. & $\mathrm{M}$ & 47 & 7 & 0 & 24 & 0 & 30 & 0 & 25 & 0 & 15 & 0 \\
\hline 27. & $\mathrm{M}$ & 54 & 8 & 0 & 39 & 3 & 45 & 0 & 15 & 0 & 15 & 0 \\
\hline 28. & $\mathrm{M}$ & 56 & 6 & 0 & 21 & 0 & 35 & 0 & 30 & 0 & 20 & 0 \\
\hline 29. & $\mathrm{M}$ & 60 & 8 & 0 & 24 & 0 & 15 & 0 & 25 & 0 & 15 & 0 \\
\hline 30. & $\mathrm{M}$ & 60 & 7 & 0 & 33 & 0 & 30 & 0 & 35 & 0 & 10 & 0 \\
\hline
\end{tabular}

Table 2:- Pre and Post VAS and Modified DALLAS Pain Score of Participants (N=30).

\begin{tabular}{|l|c|c|c|c|c|c|c|c|c|}
\hline \multirow{2}{*}{ SCORE } & \multicolumn{2}{|c|}{ Pre Score } & \multicolumn{2}{c|}{ Post Score } & df & 't' test & 'p' & \multicolumn{2}{c|}{ 95\% CI } \\
\cline { 2 - 8 } & Mean & S.D & Mean & S.D & & & value & Lower & Upper \\
\hline VAS Score & 7.17 & 1.14 & 0.07 & 0.25 & 29 & 35.55 & 0.00 & 6.69 & 7.50 \\
\hline Daily Activities & 33.86 & 14.43 & 1.30 & 2.32 & 29 & 13.37 & 0.00 & 27.58 & 37.54 \\
\hline $\begin{array}{l}\text { Work and Leisure } \\
\text { activities }\end{array}$ & 27.5 & 10.48 & 0.5 & 1.52 & 29 & 14.01 & 0.00 & 23.05 & 30.94 \\
\hline $\begin{array}{l}\text { Anxiety \& } \\
\text { Depression }\end{array}$ & 33.3 & 12.68 & 0.83 & 2.30 & 29 & 14.72 & 0.00 & 27.98 & 37.01 \\
\hline Social Interaction & 22.66 & 9.16 & 0.33 & 1.26 & 29 & 13.92 & 0.00 & 19.05 & 25.61 \\
\hline
\end{tabular}

Note- 'P' value $<0.05$ is significant,

Table-2 showed the pre and post VAS and modified DALLAS pain score of participants. 
The paired ' $\mathrm{t}$ ' test was applied to find out the significance difference between pre-score and post-score at $\mathrm{p}<0.05$ at level of significance.

The mean score of VAS in pre test was $7.17 \pm 1.14$ whereas in post test it was $0.07 \pm 0.25$. The paired ' $t$ ' test revealed that there was significant difference in VAS score before and after ischemic pressure therapy.

The pre-test mean score of daily activities was $33.86 \pm 14.43$ whereas in post test it was $1.30 \pm 2.32$ and the calculated ' $t$ ' value was 13.37. The mean score of work and leisure activities in pre test was $27.5 \pm 10.48$ whereas in post-test it was $0.5 \pm 1.52$ and the calculated ' $t$ ' value was 14.01 . The pre-test mean score of anxiety \& depression was $33.3 \pm 12.68$ whereas in post test it was $0.83 \pm 2.30$ and the calculated ' $t$ ' value was 14.72 . The pre test mean score of social interaction was $22.66 \pm 9.16$ whereas in post test it was $0.33 \pm 1.26$. The response of the patients to treatment was measured in terms of five principal parameters. One of these was Visual Analogue scale (VAS) and four of these were from Modified DALLAS Pain Questionnaire. The paired ' $t$ ' test revealed that there was significant difference in DALLAS pain score before and after ischemic pressure therapy.

The differences in five parameters of females and males before treatment were not significant, highlighting equality of pre-treatment conditions of patients across gender (Table 2).

Table 3:- A pre-treatment comparison of responses of female $(n=13)$ and male $(n=17)$ patients in their activities. The values are expressed as mean $\pm \mathrm{sd}$.

\begin{tabular}{|l|c|c|c|c|}
\hline Parameters & Female & Male & t value & p value \\
\hline VAS & $7.08 \pm 1.32$ & $7.24 \pm 1.03$ & 0.36 & 0.724 \\
\hline Daily Activities & $34.23 \pm 20.03$ & $33.59 \pm 8.74$ & 0.11 & 0.915 \\
\hline Work \& Leisure Activities & $29.23 \pm 10.58$ & $26.18 \pm 10.54$ & 0.79 & 0.440 \\
\hline Anxiety\& Depression & $30.77 \pm 7.87$ & $35.29 \pm 15.36$ & 1.05 & 0.305 \\
\hline Social-Interest & $22.69 \pm 9.92$ & $22.65 \pm 8.86$ & 0.01 & 0.990 \\
\hline
\end{tabular}

Similarly, the differences in five parameters of females and males after treatment were not significant, highlighting equality of post-treatment conditions of patients across gender (Table 4).

Table 4:- A post-treatment comparison of responses of female $(n=13)$ and male $(n=17)$ patients in their activities. The values are expressed as mean $\pm \mathrm{sd}$.

\begin{tabular}{|l|c|c|c|c|}
\hline Parameters & Female & Male & t value & p value \\
\hline VAS & $0.08 \pm 0.28$ & $0.00 \pm 0.00$ & 1.00 & 0.337 \\
\hline Daily Activities & $1.38 \pm 2.90$ & $1.24 \pm 1.86$ & 0.16 & 0.873 \\
\hline Work \& Leisure Activities & $0.77 \pm 1.88$ & $0.29 \pm 1.21$ & 0.79 & 0.437 \\
\hline Anxiety\& Depression & $0.77 \pm 1.88$ & $0.88 \pm 2.64$ & 0.14 & 0.892 \\
\hline Social-Interest & $0.38 \pm 1.39$ & $0.29 \pm 1.21$ & 0.19 & 0.853 \\
\hline
\end{tabular}

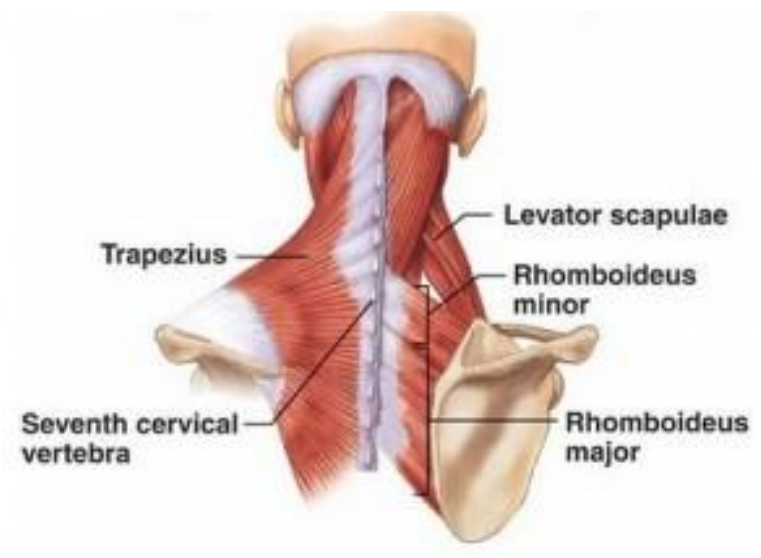

Fig 2:- Rhomboids muscles and other Muscles connecting the upper extremity to the vertebral column [14]. 


\section{Discussion:-}

Musculoskeletal causes of chest pain are common but frequently overlooked. The musculoskeletal system is a recognized source of chest pain. However, despite the apparently benign origin, patients with musculoskeletal chest pain remain under-diagnosed, untreated, and potentially continuously disabled in terms of anxiety, depression and in their ability to perform activities of daily living [15].

It is estimated that musculoskeletal problems account for $20-25 \%$ of non-cardiac chest pain. Historical features suggesting a musculoskeletal cause include pain on specific postures or physical activities. A musculoskeletal diagnosis can usually be confirmed by clinical examination alone, the key to which is reproducing the patient's pain by either a movement or more specifically palpation over the structure that is the possible source of the pain. Confirming the diagnosis, explanation and reassurance allays the anxiety of the patient to a considerable extent. Management strategies include manual therapy, the provision of analgesia and anti-inflammatory agents, either topically, orally or by injection. Focal injection of local anaesthetic alone may also be a useful diagnostic and therapeutic tool [15].

Approximately $30 \%$ of coronary angiograms are negative for significant coronary artery disease and patients are classified as having non cardiac chest pain (NCCP). So far, no systematic diagnostic approach to patients with NCCP exists apart from investigating for possible esophageal, psychiatric and musculoskeletal abnormalities. Furthermore, coping strategies and quality of life are poorly characterized in NCCP patients [16].

Acute chest pain is a major health problem all over the western world and perhaps the rest of the world as well. Active approaches are directed towards diagnosis and treatment of potentially life threatening conditions, especially acute coronary syndrome and ischemic heart disease. However, according to the literature, chest pain may also be due to a variety of extra-cardiac disorders including dysfunction of muscles and joints of the chest wall or the cervical and thoracic part of the spine. The diagnostic approaches and treatment options for this group of patients are scarce and formal clinical studies addressing the effect of various treatments are lacking [17].

The clinical symptom of anterior chest pain generally elicits a long list of diagnoses. When cardiac and pleural conditions are excluded, conditions that affect the musculoskeletal system become important considerations. Many of these conditions have characteristic imaging features that allow accurate diagnosis [18].

The thoracic region has a complex nerve supply [19]. The chest wall is largely supplied by the intercostal nerves. The shoulder girdle muscles originally develop in the lower cervical region and draw their innervation with them as they migrate to get attached to the chest wall. Thus, pain of cervical origin may be appreciated by the patient as arising in the pectoral or peri scapular region.

The rhomboid major is a skeletal muscle on the back that connects the scapula with the vertebrae of the spinal column .The rhomboid major arises from the spinous processes of the thoracic vertebrae from T2 to T5 as well as the Supraspinous ligament. It inserts on the medial border of the scapula, from about the level of the scapular spine to the inferior angle of scapula. The rhomboid major is a superficial back muscle. It is deep to the trapezius, and is located directly inferior to the rhomboid minor. The rhomboid major helps to hold the scapula (and thus the upper limb) onto the rib-cage. Other muscles that perform this function include the serratus anterior and pectoralis minor. The rhomboid major is innervated by the ventral primary ramus via the dorsal scapular nerve (C5).

Knowledge of these anatomic considerations is important in our understanding of pain referral syndromes involving the chest wall.

In our study Patients with Rhomboids muscle trigger point as the cause of chest pain were treated with Ischemic pressure and the pressure was maintained 60 seconds to 2 minutes, until the pain subsided.

Study by Hou etal compared 30seconds, 60seconds and 90seconds duration with pressure loading pain threshold and averaged value of pain threshold and pain tolerance. He found that the lower pressure at pain threshold level for duration of 90seconds was effective in obtaining pain relief. The pressure that is applied to the MTrP of taut band should be within a tolerable pain level for individual patients to avoid causing excessive pain and autonomic responses with involuntary muscle tensing $[13,20]$. 
Ischemic compression technique is non invasive \& seems to be free of adverse effects if applied after accurate diagnosis with knowledge of regional anatomy. This technique can be used as a prophylactic or preventive measure. The virtue of this technique is that it is painless \& imposes no additional strain on any associated trigger points \& there by avoids aggravating them [8]. Even though, algometer were extensively used for outcome measure of myofascial therapy, it has been rarely used to measure the quantity of delivered pressure during Ischemic Compression for management of MTrP.

The efficacy of applied Ischemic pressure may be attributed to, decreasing of hyper tonicity apparently by releasing the contracted sarcomeres in the TrP nodule [21], a mechanical stress on the colloidal matrix, which may alter its state from that of a gel to sol [22], the overriding of neural reflex mechanism, thereby reducing spasm through gating mechanism [21,22], blanching to tissues, which is followed by flushing of blood that brings oxygen and nutrients [22], release of endorphins and enkephalins [13, 22], neurological inhibition that is achieved by means of the sustained barrage of efferent information resulting from the constant pressure [13,21], and alternation of energy flow along hypothesized meridians according to the acupuncture and acupressure concepts [22]. Kostopoulos et al. compared efficacy of ischemic compression, passive stretching, and the combination of ischemic compression and passive stretching for the first time and reported that the combination was significantly more effective for pain reliefs than the others [23].

Lake et al. evaluated the efficacy of ischemic compression on 13 patients with 40 myofascial trigger points and reported that ischemic compression was significantly efficient for treatment in comparison

In 1999, David Simons discovered that a Trigger Point is a dysfunction that occurs at the point where a nerve enters a muscle. Trigger Points create shortened muscles which often compress nearby nerves. This compression irritates the nerve and distorts the nerve signal transmissions. This can lead to irregular sensations such as numbness, tingling, and burning. The Brachial Plexus is a network of nerves originating in the neck, and supplying the neck, upper back, shoulders, arms, forearms, and hands. This explains why many Trigger Points found in the neck and upper back can lead to pain and dysfunction throughout the upper body.

A Myofascial TP is a hyperirritable focal point within a taut band of skeletal muscle fibers. On compression, it can evoke typical referred pain and autonomic phenomena. A Myofascial TP is located in skeletal muscle and its associated fascia distinguished from a TP in other tissues such as skin, ligament and periosteum [12].

In our series, we found Rhomboids muscle trigger points as the cause of chest pain. In our search of Literature, we do not find any reference pertaining to this (MTrP in Rhomboids muscle) as the cause of chest pain.

Trigger Points can be either active or latent. Active Trigger Points cause pain, restriction of movement and muscular weakness. Latent trigger points cause restriction of movement and muscular weakness but 'do not' cause pain. Latent TPs can remain in muscle tissue for years after apparent injury recovery yet remain clinically silent until activated by minor overstretching, overuse or chilling of the muscle when an acute attack of pain ensues. Both Active and Latent TPs cause dysfunction but only active TPs cause pain [12]. Healthy muscle tissue does not contain TPs, which means there are no taut bands, focal tenderness or pressure induced pain referral and local twitch responses. Both sexes and all ages can develop TPs and sedentary, middle-aged women who engage in novel, repetitive or over activity are very vulnerable. Excepting later years, women are more prone to trigger points than men $[25,26,27]$.

Women are also more likely than men to seek medical assistance for TP related pain [28]. This study does not specify chest pain as the predominant musculoskeletal pain while mentioning the sexual difference in patients presenting with Myofascial Pain Syndrome (MFPS). Although, in our series males formed the majority of the patients, perhaps that female population is more confined to household work while man sought medical assistance, as their chest pain affected their working and ability to earn. However more such studies may be conducted to analyse the gender difference if applicable to chest pain as presenting complaint in patients with MFPS [29]. Children can also develop trigger points and in our study also we had one child suffering from Rhomboid Muscle trigger point leading to chest pain. 
The frequency of Active TPs increases with age and level of activity into the most active middle years with diminishing TP prevalence in later years where chief symptoms are the stiffness and restricted motion of latent TPs [12].

Performa used for Assessment of these Patients:-

1. Known causes ruled out- History

2. Investigations:

$>$ Electro cardiogram (ECG)

$>$ Echo Cardiography

$>$ Chest X-ray

$>\operatorname{Hemogram}(\mathrm{Hb}, \mathrm{TLC} / \mathrm{DLC}, \mathrm{ESR})$

$>$ CRP ( C-Reactive protein)

$>$ Blood Sugar(Random)

$>$ Serum Urea

$>$ Serum Rheumatoid factor (RA)

> Serum Calcium/Phosphate/Alkaline phosphatase

X-Ray- Cervical spine (Antero-Posterior and Lateral Views)

Dorsal spine (Antero-Posterior and Lateral Views)

\section{Inclusion criteria:-}

Musculoskeletal chest pain

\section{Exclusion criteria:-}

$>$ Acute coronary syndrome/ ischemic heart disease

$>$ Pleurisy

$>$ Pulmonary lessons like COPD, COAD and Bronchiectasis,

$>$ Costochondritis,

$>$ Teitze syndrome,

$>$ Chest wall syndrome

$>$ Rheumatologic conditions,

$>$ Infections in the chest wall

$>$ Gastro-intestinal problems and

$>$ Neoplastic disorders.

\section{Conclusion:-}

The musculoskeletal system is a recognized source of chest pain and contributes significantly to health related medical issues. It is very important for the clinician to have a thorough understanding and knowledge of various causes of cardiac and non cardiac chest pain including musculoskeletal system disorders for optimal management and outcome.

Our study has highlighted that while evaluating such cases a clinician should remember that Rhomboid Muscle trigger point can be a distressing cause of chest pain which can be effectively taken care of by Ischemic compression therapy and thus helping such patients of So called "Non Specific cardiac chest pain" who otherwise run from pillar to post or one department to another, in vain.

However, due to the paucity of literature on this association and small sample size of our study, more elaborate cross sectional studies may be required to firmly establish this association in future. 


\section{References:-}

1. Stochkendahl MJ, Christensen HW. Chest pain in focal musculoskeletal disorders. Med Clin North Am. 2010 Mar; 94 (2): 259-73. doi: 10.1016/j.mcna.2010.01.007.

2. Adel G. Fam, Hugh A. Smythe: Musculoskeletal chest wall pain, Current Reviews. CAN MED ASSOC J, VOL. 133, SEPTEMBER 1, 1985; 379-389.

3. Wehrmacher WH: The painful anterior chest wall syndromes. Med Clin North Am 1958; 38: 111-118.

4. Braunwald E: Chest pain and palpitation. In Petersdorf RG, Adams RD, Braunwald E et al (eds): Harrison's Principles of Internal Medicine, 10th ed, McGraw, New York, 1983: 25-31.

5. Levene DL: Chest Pain: an Integrated Diagnostic Approach, 1st ed, Lea \& Febiger, Philadelphia, 1977

6. Wolfe E, Stern S: Costosternal syndrome: its frequency and importance in differential diagnosis of coronary heart disease. Arch Intern Med 1976; 136: 189-191.

7. Robert D. GerwinS. Mense and R.D. Gerwin (eds.), Chapter 2- Myofascial Pain Syndrome Muscle Pain: Diagnosis and Treatment, \# Springer-Verlag Berlin Heidelberg 2010 DOI 10.1007/978-3-642-05468-6_2.

8. Simons DG, Travell JG, Simons LS. Travell and Simons' Myofascial Pain and Dysfunction: The Trigger Point Manual. Vol.1. 2nd ed. Baltimore, MD: Williams \& Wilkins, 1999.

9. Calabro JJ, Jeghers H, Miller KA et al: Classification of anterior chest wall syndromes JAMA 1980; 243: 14201421.

10. Smythe HA: Fibrositis and other diffuse musculoskeletal syndromes. In Kelley WN, Harris ED, Ruddy S et al (eds): Textbook of Rheumatology, 1st ed, Saunders, Philadelphia, 1981: 485-493

11. Frederick Wolfe,Daniel J.Clauw, Mary-Ann Fitzcharles, Muhammad B.Yunus etal. Arthritis Care \& Research 2010;62(5) 600-610 DOI 10.1002/acr.20140c 2010 American College of Rheumatology.

12. Travell Janet G., Simons David G. Trigger Points Introduction 1983.Myofascial pain and dysfunction-the trigger point manual .428 E. Preston Street Baltimore, Md 21202, U.S.A:Williams \& Wilkins.

13. Hou CR, Tsai LC, Cheng KF, Chung KC, Hong CZ. Immediate effects of various physical therapeutic modalities on cervical myofascial pain and trigger-point sensitivity. Arch Phys Med Rehabil. 2002 Oct; 83(10): 1406-14.

14. rpm-therapy.com/2011/trigger-point-muscle-pain-rhomboids

15. Jensen S Musculoskeletal causes of chest pain Aust Fam Physician. 2001 Sep; 30(9): 834-9.

16. Husser D, Bollmann A, Kuhne C Molling J, Klein HU, Evaluation of non cardiac chest pain: diagnostic approach, coping strategies and quality of life, Eur J Pain 2006 Jan; 10(1): 51-5.

17. Stochkendahl MJ, Christensen HW, Vach W, Hoilund-Carlsen PF, Haghfelt T, Hartvigsen Diagnosis and treatment of musculoskeletal chest pain: design of a multi-purpose trial J BMC Musculoskelet Disord. 2008 Mar 31; 9:40.

18. Habib PA ${ }^{1}$, Huang GS, Mendiola JA, Yu JS Anterior chest pain: musculoskeletal considerations. Emerg Radiol. 2004 Aug; 11(1):37-45. Epub 2004 Jun 10.

19. Gilbert JAL: The diagnosis of chest pain. Medicine North Am 1980; 1: 23-33

20. Travell JG, Simons DG. Cervical myofascial pain and trigger point sensivity. Arch. Phys Med Rehabilitation, 83:1406-14.

21. Njoo. KH. The occurrence and inter-ratter reliability of myofascial trigger point in the Quadrates Lumborum and gluteos Medius: A prospective study in non specific low back pain patients and controls in general practise pain, 58:317 - 232:1994.

22. Chaitow L,De Lany J. Clinical application of neuromascular techniques, in Alternative answers to pain, Churchill Livingstone:2000.

23. Lake DA, Wright LL, Cain J, Nail R, White L. The effectiveness of ischemic pressure and ischemic pressure combined with stretch on myofascial trigger points. J Orthop Sports Phys Ther. 2009; 39: A70.

24. Hanten WP, Olson SL, Butts NL, Nowicki AL. Effectiveness of a home program of ischemic pressure followed by sustained stretch for treatment of myofascial trigger points. Phys Ther. 2000; 80: 997-1003. [PubMed].

25. Solberg Solberg WK. Woo MW, Houston IB: Prevalence of mandibular dysfunction in young adults. 1 Am Dent Assoc 98:25-34. 1979.

26. Agerberg Agerberg G, bsterberg T: Maximal mandibular movements and symptoms of mandibular dysfunction in 70-year-old men and women. Swed Dent J 67:147-163.1974.

27. Kraft GH, Johnson EW, LaBan MM: The fibrositis syndrome. Arch Phys Med Rehabil 49: 155- 162, 1968.

28. Sharav Y, Tzukert A, Refaeli B; Muscle pain index in relation to pain, dysfunction, and diz- ziness associated with the myofascial pain-dys- function syndrome. Oral Surg 46; 742-747, 1978.

29. Bales T, Grunwaldt E: Myofascial pain in childhood. J Pediatr 53:198-209, 1958. 